RESTAURANTS IN THE US

\author{
Jintao (Emily) Ma \\ Lecturer \\ Department of Tourism, Leisure, Hotel and Sport Management \\ Griffith University \\ Brisbane, Queensland, Australia \\ Email: emily.ma@okstate.edu \\ Hailin Qu \\ Regents Professor and William E Davis Distinguished Chair \\ School of Hotel and Restaurant Administration \\ Oklahoma State University, Stillwater, OK74078 \\ Email: h.qu@okstate.edu

\begin{abstract}
David Njite
Assistant Professor

School of Hotel and Restaurant Administration

Oklahoma State University, Stillwater, OK74078

Email: david.njite@okstate.edu
\end{abstract}

\author{
And \\ Su Chen \\ PhD Student \\ School of Statistics \\ Oklahoma State University \\ Email: su.chen@okstate.edu
}




\title{
WESTERN AND ASIAN CUSTOMERS' PERCEPTION TOWARDS A CHINESE RESTAURANTS IN THE US
}

\begin{abstract}
Chinese food is one of the three most popular ethnic foods in the United States (US). However, relative little research attention has been paid to this segment, especially in the areas of service quality and customer satisfaction. This study is conducted in a Chinese restaurant located in Mid-west, US. The purpose of this study is threefold: to identify the determinant factors of customers' satisfaction, the relationship between customers' satisfaction and revisit intention and to examine the moderating effect of culture on these relationships. The study revealed that three aspects of Chinese restaurant service performance determine customers’ overall satisfaction, and customers' overall satisfaction is a significant mediator of customers’ revisit intention. Finally, culture moderated the relationship between employees' service performance and customers' overall satisfaction.

Key Words: Chinese Restaurant, Service Quality, Satisfaction, Revisit Intention, Ethnic Group
\end{abstract}




\section{INTRODUCTION}

\section{Diversity of the US Population and the Evoke of Ethnic Cuisines}

Italian, Mexico and Chinese cuisines have been ranked as the top three most popular ethnic cuisines in the US (Lee, 2008). Besides the unique tastes and presentations, the success of ethnic cuisine relies greatly on the highly diversified population of US. For example, Hispanic population has exceeded 15\% of the whole population of US (US Census, 2008), while Asian population composed about $4.43 \%$ of the US population. In addition, the US Census (2008) predicted that the Hispanic population will compose $24.4 \%$ of the total US population, and the Asian population will account for $8 \%$ of the whole population by 2050 . The change of the population components provides great opportunity for the expansion and development of ethnic cuisine in the US. At the same time, it also calls for more research attention to be devoted to the needs and perceptions of customers from different culture/ethnic backgrounds.

As one of the most popular ethnic cuisines in US, the total number of Chinese restaurants has exceeded the total number of McDonalds and Burger King combined (Lee, 2008). There were more than 46,700 Chinese restaurants in US in 2009 according to the statistics of Chinese Restaurant News (CRN). The Chinese restaurant industry has grown to be an important sector in the foodservice industry in US, with a sales total exceeding \$20 billion annually (CRN, 2009). The rapid growth of Chinese restaurants, however, made this segment very competitive. To cope with this, many Chinese restaurants adopted several survival strategies including: providing extended opening hours, lowering the labor costs and adopting price reduction in order to gain bigger market shares. According to the Chinese Restaurant News (CRN, 2009), 72\% of the Chinese restaurants open 7 days a week, 365 days a year. However, Chinese restaurants seem to have neglected one important aspect that can determine the success of a business in the 
restaurant sector, thus, service. Researchers have pointed out that Chinese restaurants are suffering from poor image as well as poor service (Liu, Qu \& Brown, 2009). However, the researchers propose that there is great room for improvement. These researchers further point out that this improvement is only possible if the managers realize the important role of service quality and customer satisfaction in the success of the businesses.

\section{Historical Development of Chinese Restaurants in US}

Chinese restaurants first appeared in US in the middle 1800s, following the first generation of railroad construction workers from China (Freeman, 2009). Since most of the Chinese immigrants were from Canton province, it followed that the first type of Chinese cuisine introduced to the US was Cantonese cuisine. The first Chinese restaurant in US was built in San Francisco, California in 1849 (Lu \& Fine, 1995), and the main customers were working-class dinners (Lu \& Fine, 1995).

The continued arrivals of Chinese immigrants from other parts of China brought in other types of Chinese cuisines, such as Sichuan cuisines, Hunan cuisines and many other regional Chinese cuisines (Freeman, 2009). The tastes and the presentations of these Chinese cuisines, however, were modified to suit the western customers. Chinese restaurants began to mushroom in the late 1980s (Char4u.com, 2008). According to the statistics, there were only 2829 Chinese restaurants in 1971 (Lao, 1975), but this number grew to 17,859 in 1987 (Kochak, 1988). Today, the total number of Chinese restaurants has exceeded 46,700 (CRN, 2009).

Chinese cuisine has remained one of the top-three ethnic cuisines in America for over two decades (Restaurant Business, 1992). Chinese restaurants in the US need to consider the preference of both Chinese customers as well as American customers, and they have developed into three types during this adaptation in the US market (Chen \& Bowen, 2001). The three types 
of Chinese restaurants are: 1. Restaurants in Chinatowns, which provide authentic Chinese cuisines; 2. Restaurants outside Chinatowns, which cater mainly to American customers; 3. Multi-unit restaurants, which appeared in the late 1970s. However, this classification standard is not consistent, since both authenticity and types of operation were used as classification standards. Authenticity refers to whether the food and environment can reflect the genuine taste and culture of the original ethnicity (Ebster and Guist, 2004). These researchers of this study believe that in the context of ethnic cuisines, using authenticity as the classification standard is more appropriate. Therefore, using authenticity as classification standard, Chinese restaurants in the US can be classified as restaurants that provide authentic Chinese food, and restaurants that provide Chinese food that has been modified to suit American customers. Examples of the authentic Chinese restaurants include the Empress Pavilion Restaurant and Shufeng Garden in Los Angeles; and the Old Sichuan in Chicago. Most Chinese buffet restaurants, and Chinese restaurants in small to medium cities in US, where Chinese immigrants are not clustered, provide Americanized Chinese foods. No-authentic Chinese restaurants can be found in every state of US (CRN, 2009).

\section{Research Objectives}

Despite the popularity of Chinese cuisines in the US, a review of literature reveals that very little attention has been paid to Chinese restaurants (Qu, 1998; Liu \& Jang, 2009; Ma, Qu \& Njite, 2009). This limited research leaves a gap in the extant literature in foodservice, specifically in the area of service quality and customer satisfaction towards ethnic cuisine. This study specifically examined the customer satisfaction of a type of Chinese restaurants whose food has been modified to suit the American culture (CRN, 2009). The foods served in this type of Chinese restaurants are not authentic or traditional Chinese cuisines. Rather, the presentations 
and flavors are modified to cater for the needs of American customers. The following research questions were developed to guide this study: (1) How do customers perceive the service quality of Chinese restaurants in US? (2) What are the determinant factors of customers' satisfaction? Specifically in the US, where the customers are highly diversified the following question was investigated: (3) How can the culture background influence customers' perceptions on service quality as well as satisfaction toward Chinese restaurants?

The specific objectives of the study are: 1 . Identify the dimensions of service quality attributes of Chinese restaurants; 2. Examine which are the determinant dimensions (factors) of customers' overall satisfaction and revisit intention; and 3. Test if customers' cultural backgrounds have a significant influence on customers' overall satisfaction and revisit intention.

\section{LITERATURE REVIEW}

\section{Determinant Factors of the Success of Chinese Restaurants in the US}

Researchers are interested in finding out the factors that make Chinese restaurants successful in US. Gordon (1992) found that bigger portion size, a variety of the menu items, great value for money, friendly people and quality of service are the major factors that make Chinese foods and restaurants popular in U.S.

Qu (1998) found that five factors significantly influenced Chinese restaurant customers’ return intention. These factors include: 1 . food and environment; 2 . service and courtesy; 3. price and value; 4. Location; and 5. advertisement and promotion.

In the context of Chinese chain restaurants, Chen and Bowen (2001) summarized ten factors that contributed to the success of Chinese chain restaurants in the US. The ten factors include: 1. A Good Concept; 2. Consistency of Food Quality; 3. Standard Food Preparation and 
Cooking processes; 4. Cost Control; 5. Training Programs; 6. Western Management and Eastern Expertise; 7. Marketing; 8. Customer Satisfaction; 9. Brand Name Awareness; and 10. Location. Recently, Liu and Jang (2009) conducted a study on a casual-dining Chinese restaurant, and found that "Food-related attributes", such as taste, menu variety, food safety and presentation; "Service-related attributes", such as dependent and consistency, friendliness and helpfulness of employees, "Atmospherics-related attributes", such as aroma, cleanliness, design and decoration, and "Other attributes", such as price and authenticity are the major determinant factors of Chinese restaurant customers’ satisfaction.

A review of previous literature reveals that food, environment and services provided by Chinese restaurants seem to be the three important factors that influence the success of Chinese restaurants in the US. In addition, the increased number of Chinese immigrants provides the market as well as the resources for Chinese restaurants to mushroom in the United States (Freeman, 2009).

\section{Service Quality, Satisfaction and Revisit Intention}

Service has three unique characteristics that distinguish it from other tangible products. These characteristics include: intangibility (Bateson, 1977; Lovelock, 1981), heterogeneity (Booms \& Bitner, 1981), and inseparability (Carmen \& Langeard, 1980) of production and consumption. Intangibility implies that services have no specific shape or weight, thus can neither be seen nor touched. Heterogeneity refers to the lack of consistency, and inseparability means that the production and consumption is simultaneous and as a result, the service process can be influenced by both the service providers and the customers. Therefore, the varied skill levels and attitudes of service providers, as well as the mood and personality of the customers can influence the service quality. Even the same service provider can not guarantee that he/she 
can provide exactly the same service at different times. Inseparability refers to that the creation and the consumption of service is the same process. We cannot store the service and save it for later.

These three unique features make it difficult to define and measure service quality. Oliver (1980) proposed the Expectancy-disconfirmation Model of satisfaction, and the approach of defining service quality and satisfaction this author proposed has been widely accepted. Service quality is then defined as how well the service level delivered matches customers' expectations (Oliver, 1980; Lewis \& Booms, 1983; Zeithaml, 1987). According to the Expectancydisconfirmation Model (Oliver, 1980), when the services provided meet or exceed customers’ expectations, customers will feel satisfied; however, when the services fail to meet customers' expectations, customers feel dissatisfied.

Several research findings support that satisfaction is a powerful predictor of customers’ revisit intention, positive word of mouth and eventual development of loyalty (e.g. Stevens et al., 1995; Yuksel and Yuksel, 2002; Oh, 2000; Qu, 1998; Kim, Ng \& Kim, 2008). In terms of measurement scale, the DINESERV is considered a reliable scale for measuring restaurant service quality in many studies (e.g. Heung, Wong \& Qu, 2000; Kim, McCahon and Miller, 2003). For example, Heung, Wong and Qu (2000) adapted the DINESERV scale to measure Hong Kong airport restaurants’ service quality, and suggested that the DINESERV is a reliable scale for measuring Chinese restaurant service quality.

\section{Culture/Ethnic Backgrounds’ and Authenticity’s Influence on Service Quality}

Culture, as most researchers agree, is an elusive concept and a difficult to define construct

(Traindis et al., 1986). Culture can take the forms of the cumulative deposit of knowledge, experience, beliefs, values, attitudes, hierarchies, religion, and materials objects and possessions 
acquired by a group of people (www.tamu.edu/classes/cosc/choudhury/culture.html). A holistic definition provided by Yau (1994) states that culture is the sum of learned beliefs, values, and customs that create behavioral norms for a given society. It is generally believed that people from Eastern cultures host different perceptions compared to people from Western cultures (Markus \& Kitayama, 1991; Nisbett, Peng, Choi, and Norenzayan, 2001). Residents of China, Japan and Korea are believed to be dominated by the Eastern culture, while residents of US, UK and Canada are considered to be dominated by the Western culture. Culture is a complex phenomenon, and is believed to be multidimensional. According to Hofstede (1980), cultures can be distinguished into the following five dimensions: 1 . Power distance, which refers to the extent to which the less powerful members of organizations and institutions accept and expect that power is unequally distributed; 2 . Individualism, which refers to the degree to which individuals are integrated into groups; 3 . Masculinity, which refers to the distribution of roles between the genders; 4. Uncertainty avoidance, which refers to the extent of a society's tolerance for uncertainty and ambiguity; and 5. Long-term orientation, which refers to the extent to which the society would like to use the resources to satisfy the current needs or to save for future's needs. Regarding the Individualism-Collectivism dimension, Hofstede (1980), presents that the United States and Canada are highly individualist cultures, whereas China, Japan and Korea are relatively collectivist.

Culture can influence customers' thinking and perception (Wang \& Mattila, 2008; Furer et al., 2002). In the context of service quality and customer satisfaction, Laroche, et al. (2004) found that Japanese customers reported lower quality perceptions and satisfaction ratings when the performance was high while reporting higher satisfaction ratings when the performance was low than US and Canadian customers. Due to the influence of the Confucian culture, Asian 
customers tend to express dissatisfaction less often (Lee, 1990), because they consider to 'save face' both for others and for themselves. Applying Hofstede's individualism-collectivism orientation, individualism oriented customers tend to be less tolerant of service delays and failures, compared with collectivism oriented customers (Furrer, Liu, and Sudharshan 2000).

Authentic cuisines maintained the original tastes, presentations and flavors, while nonauthentic cuisines adjusted to meet the local tastes (Ebster and Guist, 2004). In the case of Chinese restaurants in US, the majority of the restaurants have modified the foods to suit American customers' preference, with the purpose of being easily accepted by American customers. However, as the number of immigrants from China increases, the Americanized Chinese foods may not be able to satisfy Chinese customers' needs and preferences.

In summary, the foodservice industry in the US has been facing fierce competition in recent decades (Stevens, Knutson and Patton, 1995). At the same time, the population in US has become more diversified. This requires the restaurants to consider the different needs of customers from different culture backgrounds. In this way, they can attract more customers to their restaurants. Chinese restaurants have been very successful in the past decades. Chinese cuisines in the US have been modified to suit Western tastes. The increased number of Chinese immigrants may require Chinese restaurants to pay more attention to Chinese customers. In order to continue with this success, they need to consider the changing ethnic composition of the population, and try to satisfy both Eastern and Western customers' needs. Bringing back the autenticity in Chinese food may be a good way. In addition, being able to understand the unique needs of customers with different backgrounds and leverage cultural factors in the service delivery process can also be a source of competitive advantage (Riddle, 1992). 


\section{METHODOLOGY}

\section{Instrument}

The survey technique was utilized for data collection. A questionnaire consisting of four parts was developed for this study. Part one was designed to collect customers' dining habit information.

Part two was designed to collect information on customers' perceptions about the Chinese restaurant's service. Twenty-two statements were adapted from previous literature (Stevens et al, 1995, Ng, 2008, and Qu, 1997). Specifically, 13 statements (e.g. location of the restaurant, variety choice of food, nutritious of the food, and reasonable price) were adapted from Qu (1997)’s study on Chinese restaurant service quality. Seven items (e.g. parking, employees dresse neatly, employees help each other, management support employee and bill calculation is correct) were adapted from Stevens et al. (1995)'s DINESERV measurement scale. Two items (e.g. hours of operation and food taste) were adapted from Kim, Ng and Kim (2008)'s study on university foodservices. The wording, however, was modified in order to suit the Chinese restaurant setting. For this part, customers were asked to rate the 22 statements on a five-point likert-type scale, with 1=Not Satisfied; 2=Somewhat Satisfied; 3=Fairly Satisfied; 4=Very satisfied and 5=Extremely Satisfied.

Part three was designed to collect customers' perception toward the overall satisfaction with the restaurant service as well as their future purchase intention. Respondents were asked to rate overall how satisfied they were with this dining experience on a scale of $1-5$, with $1=$ Not satisfied and 5=Extremely Satisfied. Then, respondents were asked to indicate how likely they would return to the restaurant on a scale of $1-5$, with $1=$ Not Likely to Return and 5=Definitely Will Return. 


\section{Reliability}

A Pilot test with 50 respondents was first performed in March, 2008. The purpose was to test the internal consistency of the measurement scale. The Cronbach's Alpha for the 22-item Chinese restaurant service quality scale was .982. Since a values of .70 or higher is considered acceptable in social science (Nunnally \& Bernstein, 1994; Santos, 1999). Therefore, the scale used for this study had high internal consistency.

\section{Sampling}

The target population of this study were customers who visited a Chinese restaurant located in the Midwest of US during June to August, 2008. This restaurant belongs to the second type of Chinese restaurants, which provides foods that have been modified to suit American customers. A census sampling method was used. All customers who visited this restaurant were politely asked for permission to participate in the survey. A questionnaire was distributed to those customers who agreed to participate in the survey by the researcher. The completed questionnaires were collected with the assistance of the staffs of the Chinese restaurant. A total of 400 questionnaires were distributed and 328 completed questionnaires were returned, representing a respondent rate of $82 \%$.

\section{Data Analysis}

Descriptive statistics (frequency, mean and standard deviation) were performed first in order to gain the general characteristics of customers who visit this Chinese restaurant.

Principal Component Analysis was performed in order to identify the underline dimensions of Chinese restaurant service quality. The analysis resulted in three factors, Employee Services and Atmosphere (Factor 1), Food Quality and Dining Environment (Factor 2), and Physical Attributes (Factor 3). 
Two regressions were performed in order to identify the determinant factors of Chinese restaurant customers' overall satisfaction and revisit intention, using culture as a dummy variable (1=American; $0=$ Asian). The two regression models are as follows:

Satisfaction'=a+ b1Factor1+b2Factor2+b3Factor3+b4 Culture

Revisit Intention'=a+b1Satisfaction+b2 Culture

The moderating effect of culture was also tested by using the hierarchical regressions. The purpose was to test if customers' cultural backgrounds moderated the relationships between each aspect of service quality and customers' overall satisfaction. The regression models for the moderating effects are as follows:

$$
\begin{aligned}
& \text { Satisfaction'=a+b1Factor1+b2Culture+b3Factor } 1 \times \text { Culture } \\
& \text { Satisfaction'=a+b1Factor2+b2Culture+b3Factor } 2 \times \text { Culture } \\
& \text { Satisfaction'=a+b1Factor3+b2Culture+b3Factor } 3 \times \text { Culture }
\end{aligned}
$$

\section{FINDINGS AND DISCUSSIONS}

\section{Profile of Respondents}

Table 1 summarizes the demographic data of the respondents who visited the Chinese restaurant during the study period. About $85 \%$ of the customers were return-customers, and only $15 \%$ of the customers were first-time customers. $43 \%$ of the respondents were female, and $57 \%$ were male. $70 \%$ of the customers were American, and $17.4 \%$ were Asian.

In terms of food preferences, American food is the most popular food (39.9\%). Chinese food ranked as the second most popular food (25.6\%). Mexican food ranked as the third most popular food (20.1\%), and Italian food ranked as the fourth most popular food (8.8\%). This is consistent with the findings of Restaurant Business (1992).

\footnotetext{
***Please Insert Table 1 Here***
} 


\section{Chinese Restaurant Service Quality Dimensions}

***Please Insert Table 2 Here***

The Kaiser-Meyer-Olkin Measure of Sampling Adequacy value was .95, and the Bartlett's Test for Sphericity was significant (.000), indicating that the data was suitable for factor analysis. The Principle Component Analysis with a Varimax Rotation was performed. The current study used a factor loading cut-off value of 0.5 for retaining items in the factor analysis. Only factors with an Eigenvalue equal to or greater than 1 were retained (Hair et al., 2005). The analysis generated three factors, which explained $65.327 \%$ of the total variance in customer satisfaction. A solution that accounts for at least $50 \%$ of the total variance is regarded as satisfactory (Hair et al, 2005). The communality of each variable ranges from .501 to .815. This indicates that the variance of the original values was captured fairly well by the three factors: Factor 1 Employee Services and Atmosphere; Factor 2 Food Quality and Dining Environment; and Factor 3 Physical Attributes. The Cronbanch's Alpha values of the three factors ranged from .846 to .927. As a values of .70 or higher is considered acceptable in social science (Nunnally \& Bernstein, 1994; Santos, 1999), the three factors generated has high internal consistency.

\section{Service Performance, Cultural Backgrounds and Overall Satisfaction}

The first regression used Factor 1, Factor 2 and Factor 3 and the Dummy Variable, culture, as the independent variables and customers' Overall Satisfaction (S) as the dependent variable. The $\mathrm{R}^{2}$ value is .604, and is statistically significant $(\mathrm{F}(3,323)=123.181, \mathrm{p}<.000)$. This can be interpreted that the customers' satisfaction level on the three aspects of services as well as customers' cultural differences explained over $60 \%$ of the variance in customers' overall satisfaction. Detailed statistics are summarized in Table 3. Table 3 shows that all three factors 
are significant indicators of customers’ overall satisfaction. Factor 2 Food Quality and Dining Environment is the strongest predictor for customers' overall satisfaction $(\beta=.599)$; Factor 1 Employee Services and Atmosphere is the second strongest predictor $(\beta=.417)$; Factor 3 Physical Attributes is the third strongest predictor of customers' overall satisfaction ( $\beta=.207)$; the dummy variable, culture ( $\beta=.072$ ), also explained $7.2 \%$ of the variability in overall satisfaction. The full regression model equation is:

$$
\begin{gathered}
\text { Satisfaction }^{\prime}=4.083+.365 \text { Factor } 1+.524 \text { Factor } 2+.181 \text { Factor3+.165Culture } \\
\text { ***Please Insert Table } 3 \text { Here*** }
\end{gathered}
$$

\section{Overall Satisfaction and Revisit Intention}

The second regression used customers' Overall Satisfaction, and the dummy variable, culture, as independent variables and Revisit Intention as the dependent variable. The results obtained were statistically significant $(\mathrm{F}(2,195)=8.445, \mathrm{P}<.000)$. However, only $8 \%\left(\mathrm{R}^{2}=.080\right)$ of the variability in customers' revisit intention was explained by customers' overall satisfaction and ethnic background. This may be due to the fact that many factors, such as availability of time and money, could influence customers' revisit intention. The results of this regression are displayed in table 4. Customers' Overall Satisfaction is positively related to customers' Revisit Intention ( $\beta=.289)$, and was statistically significant $(\mathrm{P}<.000)$. The dummy variable, culture, did not have a statistically significant influence on the revisit intention of the respondents. The full model regression equation is:

$$
\begin{aligned}
\text { Revisit Intention }{ }^{\prime}=1.992+0.338 \text { Satisfaction } \\
\\
* * * \text { Please Insert Table } 4 \text { Here }{ }^{* * *}
\end{aligned}
$$

\section{Moderating Effects of Cultural Background \\ Hierarchical Regressions---Service Performance and Satisfaction}


A series of hierarchical regressions were performed in order to test for the moderating effect of culture on the relationships between the three service quality factors and overall satisfaction. The steps for hierarchical regressions were as follows:

Step 1 Center the scores of the independent variables (Factor 1, Factor2 and Factor 3). The purpose for centering the scores is to make the coefficients more interpretable (Aguinis, 2004).

Step 2 Create the cross-products terms using each of the three factors and the dummy variable, Culture.

Step 3 Test the moderating effect of culture on the relationship between Factor 1 and Satisfaction. Use Satisfaction as dependent variable, enter Centered Factor 1 and Culture as independent variables in the first block; then enter the cross-product of centered Factor 1 and Culture as independent variable in the second block.

Step 4 Test the moderating effects of Culture on the relationship between Factor 2 and Satisfaction, as well as between Factor 3 and Satisfaction following the same procedure.

Table 5 summarizes the results of the three hierarchical regressions. Table 5 shows that only the interaction effect of the first hierarchical regression was significant. The rest of the interactions were not significant. In the first hierarchical regression (Centered Factor 1, Culture, and Culture * Centered Factor 1 as independent variables), the addition of the cross-product term of culture and Centered Factor $1(\mathrm{CF} 1)$ resulted in a $\mathrm{R}^{2}$ change of $0.008, \mathrm{~F}(2,325)=4.620$, $\mathrm{P}<0.05$. This finding supports the presence of a moderating effect. In other words, the moderating effect of culture explains $0.8 \%$ of variance in overall satisfaction in addition to CF1's main effect.

For the first hierarchical regression, the regression equation including the moderating effect is: 
Satisfaction'=a+b1Factor1+b2Culture+b3Factor1×Culture

Since culture moderated the relationship between F1 (Employee Services and Atmosphere) and Overall Satisfaction, the regression equation is:

Satisfaction' $=4.051+1.001 \mathrm{CF} 1+0.238$ Culture $-0.25 \mathrm{CF} 1 \times$ Culture

Since American customers were coded as Culture $=1$, so the regression equation for American customers is:

Satisfaction' $=4.051+1.001 \mathrm{CF} 1+0.238(1)-0.25 \mathrm{CF} 1 \times(1)$

Satisfaction' $=4.289+0.751 \mathrm{CF} 1$

Since Asian customers were coded as Culture $=0$, so the regression equation for Asian customers is:

Satisfaction' $=4.051+1.001 \mathrm{CF} 1+0.238(0)-0.25 \mathrm{CF} 1 \times(0)$

Satisfaction' $=4.051+1.001 \mathrm{CF} 1$

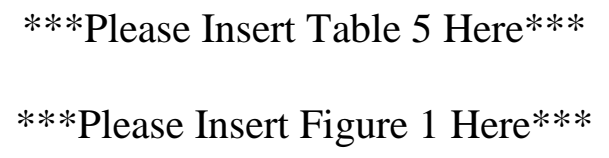

The two regression equations show that in our study context, with the same level of performance on Factor 1 Employee Services and Atmosphere, Asian customers have higher level of Overall Satisfaction than American customers. In order to show this relationship more clearly, a graph was used to display the relationship between service performance on "Employee Services and Atmosphere (Factor 1)' and American and Asian customers' Satisfaction (Figure 1). Two points, one standard deviation above and below the mean of the Factor 1, were used to plot the slopes as suggested by Aguinis (2004). 


\section{DISCUSSION, IMPLICATIONS \& FUTURE RESEARCH}

This study aimed to identify the dimensionality of Chinese restaurant service quality attributes, as well as indentifying the determinant factors of customers' overall satisfaction and revisit intention. The impact of ethnic backgrounds on customers' service quality and revisit intention were also tested.

The factor analysis generated three factors from the 22 service quality attributes, including F1: Employee Services and Atmosphere; F2: Food Quality and Dining Environment; and F3: Physical Attributes. The three factors explained over 65\% of the total variance. All of the three factors are significant predictors of customers' Overall Satisfaction, and F2: Food Quality and Dining Environment explained most of the variance in customers' Overall Satisfaction ( $\beta=0.599)$. This implied that Food is still the most important factor that influences customers' satisfaction with Chinese restaurant experience. This is consistent with previous researchers' findings (e.g. Qu, 1998; Gordon, 1992). Therefore, managers of Chinese restaurant need to pay special attention to the food quality they provide to customers. To be specific, the food should taste good, be nutritious, and the quality should be consistent. In addition, employee services ( $\beta=0.417)$ and the environment of restaurant $(\beta=0.207)$ are also important factors that will influence customers' overall satisfaction. Restaurant managers should also pay special attention in training employees' service attitude and skills to make sure that they could provide the proper level of services to customers. In terms of physical attributes or environment, keeping the restaurant clean is of critical importance to the success of any restaurant. In addition, convenient location and parking and convenient operating hours of the restaurant are also important.

The study also revealed that customers' Overall Satisfaction is a significant predictor for customers' Revisit Intention, explaining 8\% of the variance. This indicates that customers' 
revisit intention is a complex mechanism, and customer satisfaction is not the only indicator for customers' revisit intention. Put it another way, even if a customer is very satisfied with the restaurant services, he/she may still not visit the restaurant again. The reason of non-visit, however, needs further exploration by researchers. Additional variables that may predict customers' revisit intention are yet to be identified for future studies.

This study also examined the moderating effects of culture on the proposed relationships. The moderating effect of culture was found to exist between Factor1 (F1) Employee Services and Atmosphere and Overall Satisfaction. The slopes showed that with the same level of Employee Services and Atmosphere, Asian customers have higher level of Overall Satisfaction than American Customers. This is consistent with Lee's (1990) findings that Asian consumers can be expected to express dissatisfaction less often because of a need to maintain group harmony influenced by the Confucius culture. Another reason might be that Asian customers may prefer Chinese food more compared to American customers. As a result, Asian customers reported higher level of satisfaction when the performance level was the same.

Several limitations face this study. The major limitation of this study is geographic location in which the study was carried out. Another limitation is related to the source of data. The findings were based on only one restaurant and non-random sampling method was used, therefore, it may not be proper to generalize the findings to other Chinese restaurants. Besides, as there are other types of Chinese restaurants in US, future research may consider using a comparative analysis approach to check if the same findings hold for different types of Chinese restaurants in US. In addition, the geographical area of this restaurant carries a relatively small number of Asian population and therefore the sample contained a small number of Asian customers. This may influence the result of the moderating effects, as only one path of the 
relationship was found to be moderated by culture. Therefore, future studies may consider including more Asian customers to see if moderating effects exist in other paths of the proposed relationships.

\section{REFERENCES}

Aguinis, H. (2004). Regression Analysis for Categorical Moderators. The Guilford Press, New York.

Bateson. J.E.G. (1977). Do we need service marketing? In Marketing Consumer Services: New Insights. Cambridge, MA: Marketing Science Institute, Report \# 77-115.

Booms, B.H. \& Bitner, M.J. (1981). Marketing strategies and organization structure for service firms. In Marketing of Services, J. Donnelly and W. George, eds., Chicago: American Marketing, 47-51.

Broyles, S.A. \& Myers, M.B. (2003). Exploring the influence of culture on the customer satisfaction process, Conference proceeding of American Marketing Association Winter Educators’ Conference: marketing theory and application, Chicago.

Carmen, J. M. \& Langeard, E. (1980). Growth strategies of service firms, Strategic Management Journal, 1, 7-22.

Carmen, J.M. (1990). Consumer perceptions of service quality: An assessment of the SERVQUAL dimensions, Journal of Retailing, 66 (1), 33-35.

Census (2005). Population of the United States by Race and Hispanic/Latino, Census July 1, 2005. Retrieved August 13, 2008, from http://www.infoplease.com/ipa/A0762156.html

Chen, S. \& Bowen, J. T. (2001). An exploratory study of determinant factors of the success of Chinese quick service restaurant chains, Journal of Restaurant \& Foodservice Marketing, 4 (4), 239. 
Char4U.com (2008). Chinese Restaurant in America. Retrieved Nov 8, 2008, from http://www.char4u.com/article_info.php?articles_id=39.

Cohen, B. (1997). The "WOW" effect: How one restaurant continues to delight customers. Cornell Hotel and Restaurant Administration Quarterly,38 (2), 74-81.

Dube, Laurette, Renaghan, Leo \& Miller, Jane (1994). Measuring Customer Satisfaction for Strategic Management, The Cornell H.R.A. Quarterly, February, pp.39-47.

Ebster, C. \& Guist, I. (2004). The role of authenticity in ethnic theme restaurants, Journal of Foodservice Business Research 7 (2), 41-52.

Freeman, N. (2009). Ethnic Cuisines: United States, Sallys Place. Retrieved Oct 24, 2009, from http://sallybernstein.com/food/cuisines/us/

Gordon, Elizabeth. (1992). 1992 Annual CREST Report. Restaurants USA, 12(10), 39-40.

Hair, J. F., Black, B., Babin, B., Anderson, R. E., and Tatham, R. L. (2005). Multivariate Data Analysis, $6^{\text {th }}$ Edition. Prentice Hall.

Heung, V.C.S., Wong, M.Y. \& Qu, H. (2000). Airport-restaurant Service Quality in Hong Kong. Cornell Hospitality Quarterly, 41, 86.

Hofstede, G. (1980), Culture’s Consequences: International Differences in Work-Related Values. Beverly Hills, CA: Sage Publications.

June, L.P. \& Smith, S.L. (1987). Service Attributes and Situational Effects on Customer Preferences for Restaurant Dining. Journal of Travel Research, 26(2), 20-27.

Kim, W. G., Ng. C. Y. N. \& Kim, Y. (2008). Influence of Institutional DINESERV on Customer Satisfaction, Return Intention and Word of Mouth, International Journal of Hospitality Management, 28 (1), 10-17. 
Knutson, B., Stevens, P., Wullaert, C., Patton, M. \& Yokoyama, F. (1990). LODGSEKV: A Service Quality Index for the Lodging Industry, Hospitality Research Journal, VoI. 14, No. 2 (1990), pp. 277-284.

Kochak, J. (1988). Market segment report: oriental. Restaurant News, 87(4), 177-192.

Lao, K. (1975). Chinese restaurant industry in the United States: Its history, development and future. A Monograph Presented to the Faculty of the Graduate School of Cornell University for the Degree of Master of Professional Studies in Hotel Administration.

Laroche, M., Ueltschy, L.C., Abe, S., Cleverland, M., \& Yannopoulos, P.P. (2004). Service quality perceptions and customer satisfaction: Evaluating the role of culture, International Journal of Marketing, 12, 3, 58-85.

Lee, C. (1990). Modifying an American Consumer Behavior Model for Consumers in Confucian Culture: The Case of the Fishbein Behavioral Intention Model, Journal of International Consumer Marketing, 3 (1), 27-50.

Lee, J. (2008). The Fortune Cookie Chronicles: Adventures in the World of Chinese Food. Retrieved March 30, 2008, from http://www.nytimes.com/2008/03/09/books/review/Stern$\underline{\text { t.html }}$

Liu, A., Qu, H., \& Brown, T. (2010). A study of the image of Chinese restaurants in U.S.A. Conference Proceeding of the $15^{\text {th }}$ Annual Graduate Student Research Conference in Hospitality and Tourism. Washington, D.C.

Liu, Y. \& Jang, S. (2009). Perceptions of Chinese restaurants in the U.S.: What affects customer satisfaction and behavioral intentions? International Journal of Hospitality Management, 28, 338-348. 
Lovelock, C.H. (1981). Why marketing management need to e different for services, in Marketing of Sciences, J. Donelly and W. George, Eds., Chicago: American Marketing, 5-9.

Lu, S. \& Fine, G. A. (1995). The presentation of ethic authenticity: Chinese food as a social accomplishment, The Sociological Quarterly, 36 (3), 535-553.

Ma, E., Qu, H., \& Njite, D. (2009). Chinese Restaurant Service Quality: An Application of the Importance-Performance Analysis (IPA). Conference Proceeding of the $14^{\text {th }}$ Annual Graduate Student Research Conference in Hospitality and Tourism, Las Vegas.

Markus, H. \& Kitayama, S. (1991). Culture and the self: Implications for cognition, emotion, and motivation. Psychological Review, 98: 224-253.

McCleary, K. W. \& Weaver, P. A. (1982). Improving employees service levels through identifying sources of customer satisfaction, International Journal of Hospitality Management, Vol. 1, No. 2, 85-89.

National Restaurant News (2009). Top 100 Chinese Restaurants Awards, retrieved Oct 25, 2009, from http://top100.c-r-n.com/AboutTop100/content.asp?nid=510190523

Nisbett , R.E., Peng, K., Choi, I., \& Norenzayan, A. (2001). Culture and systems of thought: Holistic vs. analytic cognition. Psychological Review, 108 (2): 291-310.

Oh, H. (2000). Diners' perception of quality, value, and satisfaction: a practical viewpoint. Cornell Hotel and Restaurant Administration Quarterly 41 (3), 58-66.

Oliver, R.C. (1980). A cognitive model for the antecedents and consequences of satisfaction decisions. Journal of Marketing Research, 17 (4), 460-469.

Qu (1998). Determinant factors and choice intention for Chinese restaurant Dining-A multivariate approach. Journal of Restaurant and Foodservice Marketing, 2(2), 35-49. 
Riddle, D. (1992). Leveraging cultural factors in international service delivery. Advances in Service Marketing and Management, 1: 297-322.

Rokeach, M. (1973). The Nature of Human Values. London: The Free Press.

Stevens, P., Knutson, B. \& Patton, M. (1995). DINSERV: a tool for measuring service quality in restaurants. The Cornell Hotel and Restaurant Administration Quarterly, April, 56-60.

Triandis, H. C., Bontempo, R., Betancourt, H. Bond, M., Leung, K., Brenes, A, et al. (1986). The measurement of the etic aspects of individualism and collectivism across cultures. Australian Journal of Psychology, 38 (3), 257-267.

Walkup, C. (2005). Resort hotels seek to boost sales, outshine competition with new signature restaurants. National Restaurant News.

Wang, Y. \& Mattila, A. (2008). The role of culture in customer references for service failure explanations. 2008 ICHRIE Proceedings, Atlanta.

Yau, O. (1994), Consumer Behavior in China. London: Routledge.

Zeithaml, Valarie (1987), Defining and Relating Price, Perceived Quality, and Perceived Value, Report No, 87-101, Cambridge, MA: Marketing Science Institute.

Yuksel, A., \& Yuksel, F. (2002). Measurement of tourist satisfaction with restaurant services: a segment-based approach. Journal of Vacation Marketing 9 (1), 52-68. 
Table 1 Demographic Profile of Chinese Restaurant Customers

\begin{tabular}{|c|c|c|c|c|c|}
\hline \multicolumn{6}{|c|}{ Customer Demographic Profile $(\mathrm{N}=328)$} \\
\hline Aspects & $\mathbf{N}$ & $\%$ & Aspects & $\mathbf{N}$ & $\%$ \\
\hline \multicolumn{3}{|l|}{ Gender } & \multicolumn{3}{|l|}{ Annual Income } \\
\hline Male & 187 & 57 & Below 20,000 & 144 & 43.9 \\
\hline \multirow{2}{*}{ Female } & \multirow{3}{*}{141} & \multirow[t]{3}{*}{43} & 20,000 to 39,999 & 58 & 17.7 \\
\hline & & & 40,000 to 59,999 & 60 & 18.3 \\
\hline First vs. Repeat & & & 60,000 to 89,999 & 42 & 12.8 \\
\hline First Time & 50 & 15.2 & \multirow[t]{2}{*}{90,000 or above } & \multirow[t]{2}{*}{24} & \multirow[t]{2}{*}{7.3} \\
\hline Repeat & 278 & 84.8 & & & \\
\hline \multicolumn{3}{|l|}{ Age Group } & \multicolumn{3}{|l|}{ Education Level } \\
\hline 20 or Below & 50 & 15.2 & Elementary School & 6 & 1.8 \\
\hline 21-35 & 145 & 44.2 & Junior High School & 8 & 2.4 \\
\hline $36-50$ & 69 & 21 & High School & 117 & 35.7 \\
\hline $51-65$ & 50 & 15.2 & Bachelor & 121 & 36.9 \\
\hline \multirow[t]{2}{*}{ Over 65} & \multirow[t]{2}{*}{14} & \multirow[t]{2}{*}{4.3} & Master & 43 & 13.1 \\
\hline & & & Ph.D. & 33 & 10.1 \\
\hline \multicolumn{3}{|l|}{ Culture Group } & \multicolumn{3}{|l|}{ Favorite Food } \\
\hline American & 232 & 70.7 & American Food & 131 & 39.9 \\
\hline Asian & 57 & 17.4 & Chinese Food & 84 & 25.6 \\
\hline \multirow[t]{5}{*}{ Others } & \multirow[t]{5}{*}{39} & \multirow[t]{5}{*}{11.9} & Mexican Food & 66 & 20.1 \\
\hline & & & Italian Food & 29 & 8.8 \\
\hline & & & Japanese Food & 12 & 3.7 \\
\hline & & & Korean Food & 5 & 1.5 \\
\hline & & & Thai Food & 1 & 0.3 \\
\hline
\end{tabular}


Table 2 Factor Analysis of Chinese Restaurant Service Quality Attributes

\begin{tabular}{|c|c|c|c|c|}
\hline \multirow[t]{2}{*}{ Factors and Variables } & \multicolumn{4}{|c|}{ Varimax rotated loadings } \\
\hline & Factor 1 & Factor 2 & Factor 3 & Communality \\
\hline \multicolumn{5}{|l|}{ F1-Employee Services and Atmosphere } \\
\hline Atmosphere & 0.530 & & & 0.501 \\
\hline Employee friendliness & 0.668 & & & 0.620 \\
\hline Bills are correctly calculated & 0.501 & & & 0.523 \\
\hline English language ability of employees & 0.667 & & & 0.572 \\
\hline Employees dress neatly & 0.736 & & & 0.686 \\
\hline Proper level of services & 0.730 & & & 0.740 \\
\hline Employees help each other & 0.781 & & & 0.735 \\
\hline Manager supports employees for services & 0.743 & & & 0.691 \\
\hline Reputation of the restaurant & 0.604 & & & 0.729 \\
\hline \multicolumn{5}{|l|}{ F2-Food Quality and Dining Environment } \\
\hline Restaurant is clean & & 0.656 & & 0.684 \\
\hline There are a variety choice of food & & 0.558 & & 0.554 \\
\hline The food quality is good & & 0.815 & & 0.791 \\
\hline The food quality is consistent & & 0.755 & & 0.710 \\
\hline The food is nutritious & & 0.564 & & 0.551 \\
\hline The food tastes good & & 0.709 & & 0.743 \\
\hline The price is reasonable & & 0.698 & & 0.671 \\
\hline The food is value for money & & 0.705 & & 0.638 \\
\hline \multicolumn{5}{|l|}{ F3-Physical Attributes } \\
\hline The location is good & & & 0.790 & 0.677 \\
\hline The parking is convenient & & & 0.784 & 0.690 \\
\hline Hours of operation is convenient & & & 0.730 & 0.706 \\
\hline Reception is quick & & & 0.547 & 0.526 \\
\hline The restaurant can cater my group size & & & 0.662 & 0.635 \\
\hline \multicolumn{5}{|l|}{ General Information } \\
\hline \% of variance explained & 25.469 & 23.629 & 16.230 & 65.327 \\
\hline Cronbanch’s alpha & 0.927 & 0.924 & 0.846 & \\
\hline Eigenvalue & 11.772 & 1.501 & 1.099 & \\
\hline
\end{tabular}


Table 3 The Relationship between Service Performance, Culture and Overall Satisfaction

\begin{tabular}{|c|c|c|c|c|}
\hline Dependent Variable & \multicolumn{4}{|c|}{ Overall Satisfaction } \\
\hline Independent Variables & \multicolumn{4}{|c|}{$\begin{array}{l}\text { F1-Employeee services \& atmosphere } \\
\text { F2-Food Quality and Dining Environment } \\
\text { F3-Physical Attributes } \\
\text { Culture (Dummy) }\end{array}$} \\
\hline Multiple R & \multicolumn{4}{|c|}{.777} \\
\hline & \multicolumn{4}{|l|}{.604} \\
\hline Adjusted $\mathrm{R}^{2}$ & \multicolumn{4}{|l|}{.599} \\
\hline Standard Error & \multicolumn{4}{|c|}{.55382} \\
\hline $\mathrm{F}$ & \multicolumn{4}{|c|}{123.181} \\
\hline $\mathrm{N}$ & \multicolumn{4}{|c|}{328} \\
\hline Independent Variables & B & Beta & $\mathrm{t}$ & Sig. \\
\hline Constant & 4.083 & & 54.234 & $.000^{* *}$ \\
\hline F1-Employeee services \& atmosphere & .365 & .417 & 11.727 & $.000^{* *}$ \\
\hline F2-Food Quality and Dining Environment & .524 & .599 & 16.846 & $.000^{* *}$ \\
\hline F3-Physical Attributes & .181 & .207 & 5.915 & $.000^{* *}$ \\
\hline Culture (Dummy) & .165 & .072 & 1.983 & $.048^{*}$ \\
\hline
\end{tabular}


Table 4 The Relationship between Overall Satisfaction, Culture and Revisit Intention

\begin{tabular}{|c|c|c|c|c|}
\hline Dependent Variable & \multicolumn{4}{|c|}{ Revisit Intention } \\
\hline Independent Variables & \multicolumn{4}{|c|}{ Overall Satisfaction } \\
\hline & \multicolumn{4}{|c|}{ Culture (Dummy) } \\
\hline Multiple R & \multicolumn{4}{|c|}{.282} \\
\hline $\mathrm{R}^{2}$ & \multicolumn{4}{|l|}{.080} \\
\hline Adjusted $\mathrm{R}^{2}$ & \multicolumn{4}{|l|}{.070} \\
\hline Standard Error & \multicolumn{4}{|c|}{1.03323} \\
\hline $\mathrm{F}$ & \multicolumn{4}{|c|}{8.445} \\
\hline $\mathrm{N}$ & \multicolumn{4}{|l|}{328} \\
\hline Independent Variables & $\mathrm{B}$ & Beta & $\mathrm{t}$ & Sig. \\
\hline Constant & 1.992 & & 5.654 & $.000^{* *}$ \\
\hline Overall Satisfaction & .338 & .289 & 4.085 & $.000^{* *}$ \\
\hline Culture (Dummy) & -.104 & -.037 & -.520 & .604 \\
\hline
\end{tabular}

${ }^{*} \mathrm{P}<.05 ;{ }^{* *} \mathrm{P}<.01$. 
Table 5 Moderating Effects of Culture on Service Performance and Overall Satisfaction

Model 1

Dependent Variable

Independent Variables

Overall Satisfaction

Centered F1

Culture

Change of $\mathrm{R}^{2}$

Culture*Centered F1

Significance of Change of $\mathrm{R}^{2}$

.008

$.032^{*}$

\begin{tabular}{lllll}
\hline Independent Variables & $\mathrm{B}$ & Beta & $\mathrm{t}$ & Sig. \\
Constant & 4.051 & & 48.09 & $.000^{* *}$ \\
Centered F1 & 1.001 & .828 & 9.956 & $.000^{* *}$ \\
Culture & .238 & .111 & 2.557 & $.011^{*}$ \\
Culture*Centered F1 & -.250 & -.175 & -2.149 & $.032^{*}$ \\
\hline
\end{tabular}

Model 2

Dependent Variable

Independent Variables

Change of $\mathrm{R}^{2}$

Significance of Change of $\mathrm{R}^{2}$
Overall Satisfaction

Centered F2

Culture

Culture*Centered F2

.005

.085

\begin{tabular}{lllll}
\hline Independent Variables & $\mathrm{B}$ & $\mathrm{Beta}$ & $\mathrm{t}$ & Sig. \\
Constant & 4.126 & & 53.153 & $.000^{* *}$ \\
Centered F2 & 1.016 & .861 & 11.617 & $.000^{* *}$ \\
Culture & .155 & .072 & 1.818 & $.07^{*}$ \\
Culture*Centered F2 & -.176 & -.125 & -1.730 & .085 \\
\hline
\end{tabular}

Dependent Variable

Independent Variables

Change of $\mathrm{R}^{2}$

Significance of Change of $\mathrm{R}^{2}$

Independent Variables

Constant

Centered F2

Culture

Culture*Centered F2

${ }^{*} \mathrm{P}<.05 ;{ }^{* *} \mathrm{P}<.01$.
Model 3

Overall Satisfaction

Centered F3

Culture

Culture*Centered F3

.002

.339

\begin{tabular}{llll} 
B & Beta & $\mathrm{t}$ & Sig. \\
3.862 & & 40.241 & $.000^{* *}$ \\
.700 & .568 & 5.924 & $.000^{* *}$ \\
.463 & .215 & 4.329 & $.000^{*}$ \\
-.132 & -.091 & -.957 & .339 \\
\hline
\end{tabular}




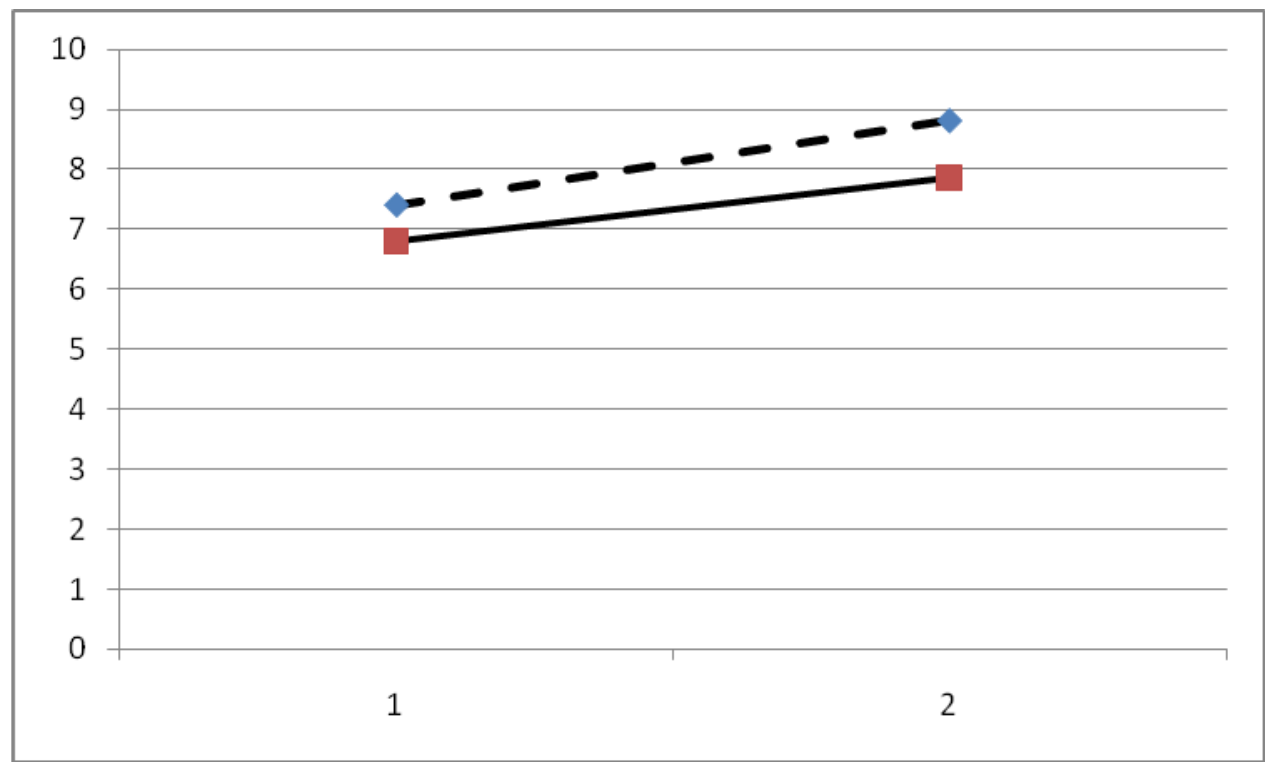

Service Performance on Factor 1

Broken Line: Asian Customers

Solid Line: American Customer

Figure 1 The Moderating Effects of Culture on the Relationship between Customers' Service Performance on Factor 1 and Customers' Overall Satisfaction 